
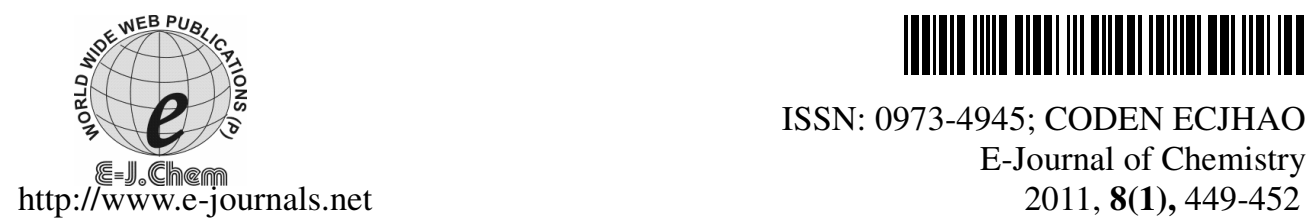

ISSN: 0973-4945; CODEN ECJHAO

E-Journal of Chemistry 2011, 8(1), 449-452

\title{
Novel and Efficient Procedure for the Preparation of Two Pyridine Dicarboxylic Acid Derivatives
}

\author{
G. U. GUOLIANG and L U. MING* \\ Chemical Engineering College \\ Nanjing University of Science and Technology, Nanjing-210094, China \\ luming@mail.njust.edu.cn
}

Received 9 May 2010; Accepted 20 July 2010

\begin{abstract}
New strategies for the synthesis of two pyridine dicarboxylic acid derivatives namely; 4-(2-(2,6-dicarboxypyridin-4-yl)vinyl)pyridine-2,6dicarboxylic acid and 2,6-bis(2-(2,6-dicarboxy-pyridin-4-yl)vinyl)pyridine have been described. New oxidant used is a good example of green chemistry technology and the synthesis procedure harvest a high-purity product at a high yield.
\end{abstract}

Keywords: Pyridine dicarboxylic acid derivatives, New oxidant, Green chemistry technology, Planar Structure.

\section{Introduction}

Our research group has recently been interested in synthesis of the pyridine dicarboxylic acid derivatives with rigid conjugated planar structure, which would be beneficial to the electronic negotiability ${ }^{1}$, as many of them are useful in the field of fiber-optic telecommunications systems $^{2 \sim 5}$ and time resolved fluoroimmunoassay $(\text { TR-FIA })^{6 \sim 7}$.

In recent years, increasing attention has been focused on organic reactions in which environmental pollution reduced and aqueous media used. To the best of our knowledge, the pyridine dicarboxylic acid derivatives have been reported only in our previous studies ${ }^{8}$ in which the PCC oxidant was used and produced the wastewater containing heavy metals. We report here the new synthesis routes, in which the oxidants sodium salt of 2-nitrpropane and recycled $\mathrm{K}_{3} \mathrm{Fe}(\mathrm{CN})_{6}$ were used. The reusability of $\mathrm{K}_{3} \mathrm{Fe}(\mathrm{CN})_{6}$ make it more attractive than previous oxidant. The synthesis routes are detailed in Scheme 1. 

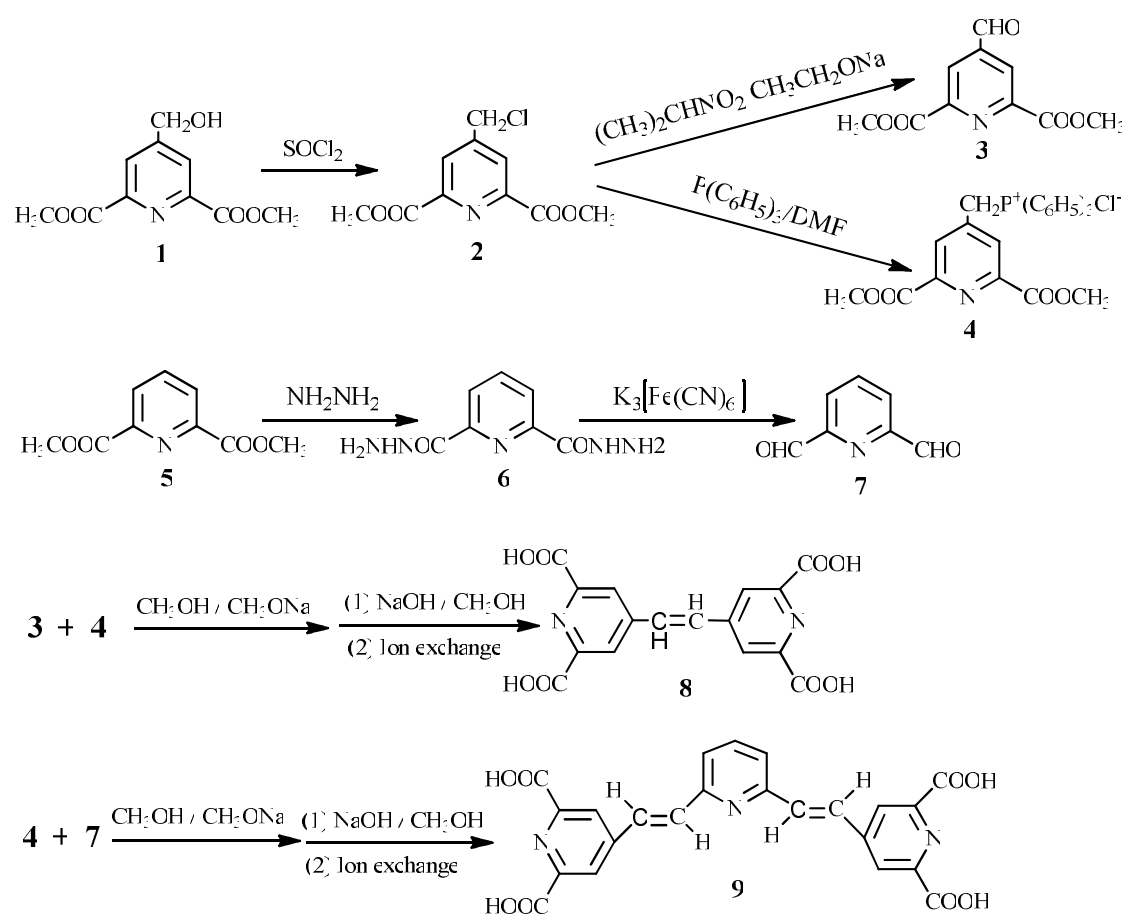

\section{Experimental}

Scheme 1

All reagents were obtained commercially and used without further purification. Melting points were determined on a XR-4 apparatus (thermometer uncorrected). Contents of carbon, hydrogen and nitrogen were determined using an Elementar vario EL elemental analyzer. Infrared spectra $\left(4000-400 \mathrm{~cm}^{-1}\right)$ were recorded with samples as $\mathrm{KBr}$ pellets on Nicolet NEXUS 670 FTIR spectrophotometer. ${ }^{1} \mathrm{H}$ NMR were measured with a Bruker$400 \mathrm{MHz}$ nuclear magnetic resonance spectrometer with $\mathrm{CDCl}_{3}$ or DMSO as solvent and TMS as internal reference. Mass spectrum was measured using a ZAB-HS analyzer.

The required intermediates named dimethyl 4-(hydroxylmethyl)pyridine-2,6-dicarboxylate (1) and dimethyl pyridine-2,6-dicarboxylate (5) were prepared using reported procedures 9

\section{Preparation of dimethyl 4-(chloromethyl)pyridine-2, 6-dicarboxylate (2)}

To a solution of compound $\mathbf{1}(3.0 \mathrm{~g}, 13.3 \mathrm{mmol})$ in anhydrous $\mathrm{CHCl}_{3}(25 \mathrm{~mL})$, sulfuryl dichloride $(2.4 \mathrm{~g}, 20.0 \mathrm{mmol})$ as added drop wise under nitrogen atmosphere at $-5^{\circ} \mathrm{C}$ with continuous stirring for $40 \mathrm{~min}$. Excess solvent was removed under reduced pressure and the crude product was purified by recrystallization from ethanol to give the flaxen solid $\mathbf{2}$ (yield $2.8 \mathrm{~g}$ ) after drying in vacuum.

\section{Preparation of dimethyl 4-formylpyridine-2, 6-dicarboxylate (3)}

Sodium (3.45 g, $0.15 \mathrm{~mol})$ was added to absolute EtOH $(250 \mathrm{~mL})$ in batches under nitrogen atmosphere and continuous stirring to the sodium solid disappeared, then 2-nitropropane $(14.00 \mathrm{~g}, 0.15 \mathrm{~mol}$ ) was added and stirred for $30 \mathrm{~min}$. The compound 2 (37.30 g, 0.15 mol) was added to the mixture solution and heated to reflux for $4 \mathrm{~h}$. Excess solvent was removed under reduced pressure. The residue was extracted by dichloromethane, then the solvent was removed to give the flaxen solid $\mathbf{3}$ (yield $39.35 \mathrm{~g}$ ) after drying in vacuum. 
Preparation of dimethyl 4-(methylenetriphenylphosphoniumchloride)pyridine-2, 6dicarboxylate (4)

A mixture of triphenylphosphine $(6.8 \mathrm{~g}, 25.0 \mathrm{mmol})$, compound $2(5.0 \mathrm{~g}, 20.0 \mathrm{mmol})$ and DMF $(10 \mathrm{~mL})$ was refluxed for $5 \mathrm{~h}$. To the above solution, the anhydrous benzene $(30 \mathrm{~mL})$ was added and refluxed for $1 \mathrm{~h}$. The reaction mixture was cooled to the room temperature and filtered to obtain the colorless solid 4 (yield $7.0 \mathrm{~g}$ ).

Preparation of pyridine-2,6-dicarbohydrazide (6)

A mixture of compound $5(19.50 \mathrm{~g}, 0.10 \mathrm{~mol})$, ethanol $(50 \mathrm{~mL})$ and hydrazine hydrate $(80 \%$, $15.0 \mathrm{~mL})$ was refluxed for $6 \mathrm{~h}$. $80 \%$ solvent was removed and water $(20 \mathrm{~mL})$ was added. Then the reaction mixture was kept for $8 \mathrm{~h}$ at $-10^{\circ} \mathrm{C}$. The white crystalline product (yield $16.8 \mathrm{~g})$ thus obtained was filtered, washed and dried.

\section{Preparation of pyridine-2, 6-dicarbaldehyde (7)}

To the mixture of compound $6(9.80 \mathrm{~g}, 0.05 \mathrm{~mol}$, ammonia aqueous solution; $25 \mathrm{~mL})$ and water $(250 \mathrm{~mL}), \mathrm{K}_{3} \mathrm{Fe}(\mathrm{CN})_{6}$ aqueous solution $(49.0 \mathrm{~g}, 0.05 \mathrm{~mol}, 150 \mathrm{~mL})$ was added dropwise at low temperature. The reaction mixture was stirred for $4 \mathrm{~h}$ at room temperature, then extracted by dichloromethane and washed with $10 \% \mathrm{Na}_{2} \mathrm{CO}_{3}$ aqueous solution. The solvent was removed to give the off-white crystalline product (yield $6.05 \mathrm{~g}$ ) after drying in vacuum.

Preparation of 4-(2-(2,6-dicarboxypyridin-4-yl)vinyl)pyridine-2,6-dicarboxylic acid ${ }^{8}$ ( 8)

To the mixture of compound $4(5.2 \mathrm{~g}, 10.0 \mathrm{mmol})$, compound $3(2.4 \mathrm{~g}, 10.0 \mathrm{mmol})$ and the absolute methanol $(100 \mathrm{~mL})$, the methanol solution of sodium methanolate $(0.8 \mathrm{~g}, 12.0 \mathrm{mmol}$, $40 \mathrm{~mL}$ ) was added dropwise and stirred for $1 \mathrm{~h}$ under nitrogen atmosphere at $-20^{\circ} \mathrm{C}$ and kept it overnight with stirring at room temperature. The solution was concentrated under reduced pressure and a whitish solid was obtained by flash chromatography eluting from ethyl acetate, petroleum ether and chloroform $(1: 1: 1, \mathrm{v} / \mathrm{v})$. A solution of $\mathrm{NaOH}(30 \%, 18.0 \mathrm{~g})$ was added into 4-(4-(2-(2,6 -bis(methoxycarbonyl)pyridine -4-yl)vinyl)styryl)pyridine-2,6dicarboxylate $(5.6 \mathrm{~g}, 10.0 \mathrm{mmol})$ in methanol $(80 \mathrm{~mL})$ and the mixture was stirred at room temperature for $30 \mathrm{~h}$. Then the $\mathrm{pH}$ was adjusted to 1 with $\mathrm{HCl}(3 \mathrm{~mol} / \mathrm{L})$. The whitish solid compound 9 (yield $3.9 \mathrm{~g}$ ) was obtained.

Preparation of 2, 6-bis(2- (2, 6 -dicarboxypyridin-4-yl) vinyl)pyridine (9)

Compound 9 was obtained following the same procedure described as compound 8.

\section{Results and Discussion}

\section{Characterization data}

Compound 2: Yield: $86.0 \%$; m.p. $168 \sim 17^{\circ} \mathrm{C}$. IR (KBr), $v / \mathrm{cm}^{-1}: 3079,2959,2836,1725,1710$, 1380, 1257, 1125, 798. MS, m/z: $243\left(\mathrm{M}^{+}\right), 213\left(\mathrm{M}^{\left.-\mathrm{OCH}_{3}, 62 \%\right),} 184\left(\mathrm{M}-\mathrm{OCH}_{3}-\mathrm{CO}, 100 \%\right)\right.$. ${ }^{1} \mathrm{H}$ NMR $\left(400 \mathrm{MHz}, \mathrm{CDCl}_{3}\right), \delta(\mathrm{ppm}): 8.27(\mathrm{~s}, 2 \mathrm{H}, \mathrm{Py}-\mathrm{H}), 4.45\left(\mathrm{~s}, 2 \mathrm{H}, \mathrm{CH}_{2} \mathrm{Cl}\right), 4.06(\mathrm{~s}, 6 \mathrm{H}$, $\mathrm{OCH}_{3}$ ). EA (calculated for $\mathrm{C}_{9} \mathrm{H}_{10} \mathrm{O}_{5} \mathrm{~N}$ ): \%C 49.65 (49.18), $\mathrm{H} 4.15$ (4.23), $\mathrm{N} 5.52$ (5.37).

Compound 3: Yield: 86.0\%; m.p.152 154 ${ }^{\circ} \mathrm{C}$; IR (KBr), v/cm-1: 3037, 2960, 2861, 1734, 1706, 1355, 1213, 978, 781. MS m/z: $165\left(\mathrm{M}^{+}\right) .{ }^{1} \mathrm{H}$ NMR (400 MHz, $\left.\mathrm{CDCl}_{3}\right), \delta(\mathrm{ppm})$ : $10.02(\mathrm{~s}, 1 \mathrm{H},-\mathrm{CHO}), 6.64(\mathrm{~s}, 2 \mathrm{H}, \mathrm{Py}-\mathrm{H}), 4.06(\mathrm{~s}, 6 \mathrm{H},-\mathrm{OCH} 3)$. EA (calculated for $\left.\mathrm{C}_{9} \mathrm{H}_{10} \mathrm{O}_{5} \mathrm{~N}\right)$ : \% C 53.65 (53.82), H 4.10 (4.06), N 6.30 (6.28)

Compound 4: ${ }^{1} \mathrm{H}$ NMR (400 MHz, $\left.\mathrm{CDCl}_{3}\right), \delta(\mathrm{ppm}): 3.90\left(\mathrm{~s}, 6 \mathrm{H},-\mathrm{CH}_{3}\right), 5.09(\mathrm{~s}, 2 \mathrm{H},-$ $\mathrm{CH}_{2}-$ ), 4.06 (s, 2H, Py), 7.68 (s, 17H, Py-H and Ar-H). 
Compound 6: Yield: 87.3\%; IR (KBr), v/ $\mathrm{cm}^{-1}: 3272,3186,1691,989$. MS m/z: 195 $\left(\mathrm{M}^{+}\right) .{ }^{1} \mathrm{H}$ NMR $\left(400 \mathrm{MHz}, \mathrm{CDCl}_{3}\right), \delta(\mathrm{ppm}): 2.12\left(\mathrm{~s}, 4 \mathrm{H}, \mathrm{NH}_{2}\right), 7.86(\mathrm{~s}, 2 \mathrm{H}, \mathrm{NH}), 8.60 \sim 8.83$ $\left(\mathrm{m}, 3 \mathrm{H},-\mathrm{C}_{5} \mathrm{H}_{3} \mathrm{~N}-\right.$ ). EA (calculated for $\mathrm{C}_{7} \mathrm{H}_{9} \mathrm{O}_{2} \mathrm{~N}_{5}$ ): \% C 43.02 (43.08), $\mathrm{H} 4.60$ (4.65), N 35.99 (35.88)

Compound 7: Yield: 84.6\%; m.p.124 127 ${ }^{\circ} \mathrm{C}$; IR (KBr), v/ $\mathrm{cm}^{-1}: 3083,1720,1692,598$. ${ }^{1} \mathrm{H}$ NMR (400 MHz, $\mathrm{CDCl}_{3}$ ), $\delta(\mathrm{ppm}): 10.21$ (s, 2H,-CHO), 8.21 (d, 2H, Py-H, J=7.2), 8.12 (t, 1H, Py-H, J=7.5).

Compound 8: Yield: 88.4\%; m.p.286 288 ${ }^{\circ} \mathrm{C}$. IR (KBr), v/cm ${ }^{-1}: 3450,2918,1734$, 1636, 1593, 1399, 1259, 981, 696. ${ }^{1} \mathrm{H}$ NMR (DMSO-d $\left.{ }_{6}\right), \delta(\mathrm{ppm}): 12.50$ (s, 4H , -COOH), 8.05 (s, 4H, Py-H ), 6.96 (d, 2H, J=17.0 Hz, Py-CH= ).

Compound 9: Yield: 87.7\%; m.p.288 290 ${ }^{\circ} \mathrm{C}$. IR (KBr), v/cm ${ }^{-1}: 3452,2923,1738$, 1635, 1598, 1340, 1257, 986, 685. ${ }^{1} \mathrm{H}$ NMR (DMSO-d 6 ), $\delta(\mathrm{ppm}): 6.91$ (d, 2H, =HC-Py$\mathrm{CH}=$ ), 7.13 (d, 2H, Py-CH= ), 7.74 8.27 (s, 7H, Py-H), 12.45 (s, 4H, COOH).

\section{Conclusion}

In conclusion, we have developed a novel and efficient synthetic pathway for the preparation of two pyridine dicarboxylic acid derivatives in more than $87 \%$ excellent yield. Compared to the synthetic methods reported in previous literature, the novel method not only enhanced the yield, but also made the operating units easy workup. Moreover, the excellent recyclability of the oxidant system makes this procedure cleaner, which is a good example of green chemistry technology.

\section{Acknowledgment}

We thank the Ministry of Education of the Republic of China and Natural Science Foundation of Jiangsu Province for support of this research.

\section{References}

1 Paul N W, J Org Chem, 2001, 66, 4170-4179.

2 Hasegawa Y, Wada Y and Yanagida S, J Photochem Photobiol C Photochem Rev, 2004, 5, 183-202.

3 Gawryszewska P, Sokolnicki J and Legendziewicz J, Coord Chem Rev., 2005, 249, 2489.

$4 \quad$ Hemmila I and Laitala V, J Fluoresc., 2005, 15(4), 529-542.

5 Bunzli J C G, Acc Chem Res., 2006, 39, 53-61.

6 Morita M, Rau D and Herren M, J Alloys Compd., 2004, 380, 260-267.

7 Sokolnicki J, Legendziewicz J, Muller G and Riehl J P, Opt Mater, 2005, 27, 1529-1536.

8 Gu G L, Tang R R, Zheng Y H and Shi X M, Spectrochim Acta Part A., 2008, 71(1), 209-214.

9. Tang R R, Zheng Y H and Zhao Q, Chem Rea Eng Technol., 2006, 22, 83. 


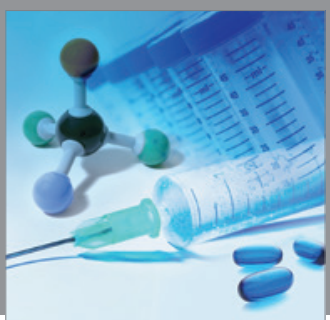

International Journal of

Medicinal Chemistry

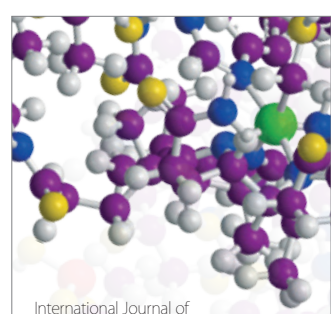

Carbohydrate Chemistry

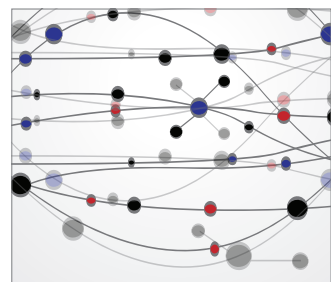

The Scientific World Journal
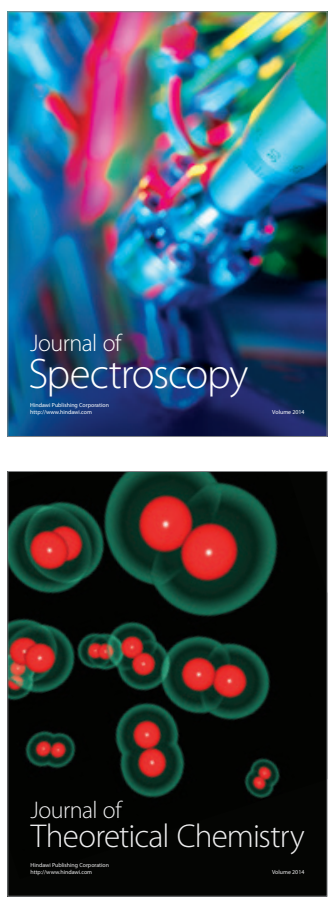
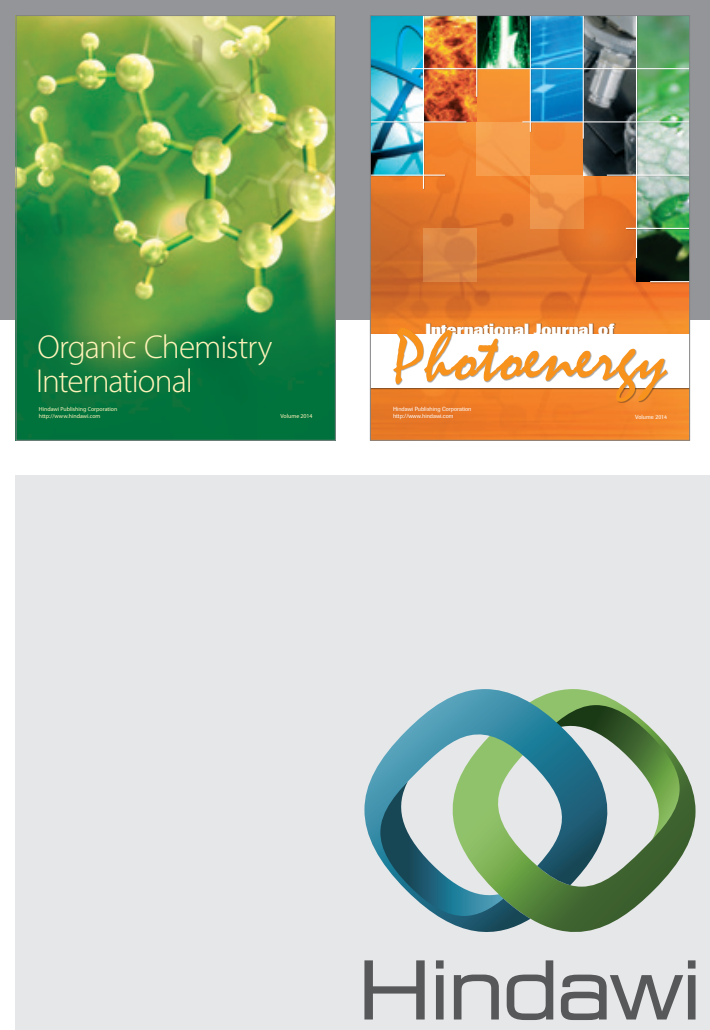

Submit your manuscripts at

http://www.hindawi.com
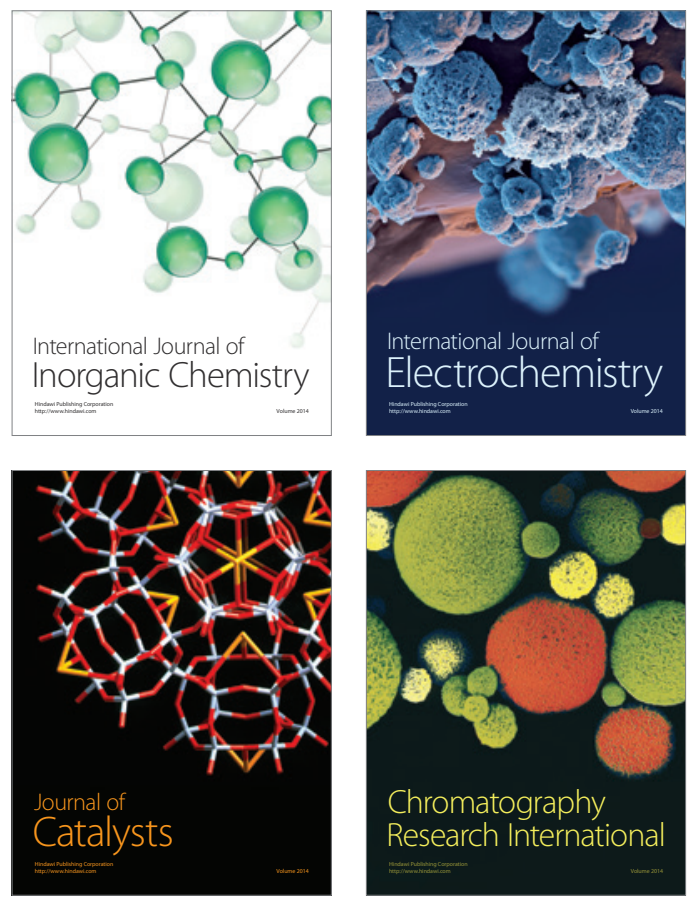
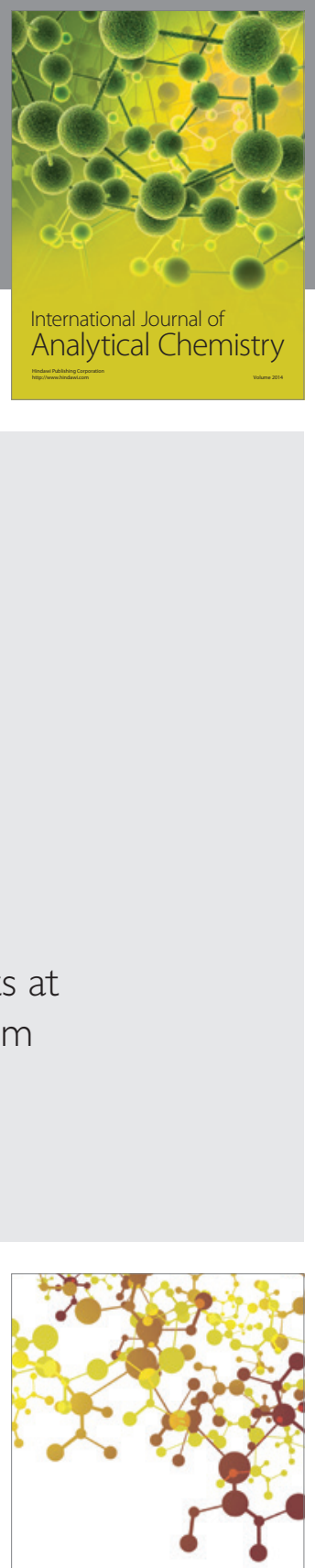

Journal of

Applied Chemistry
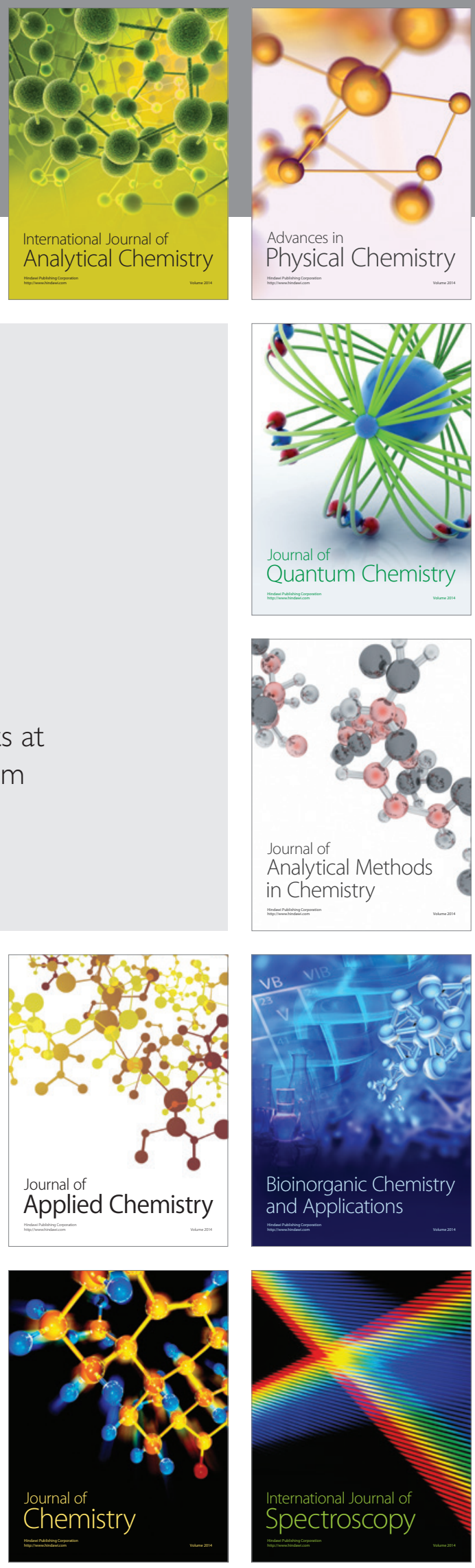